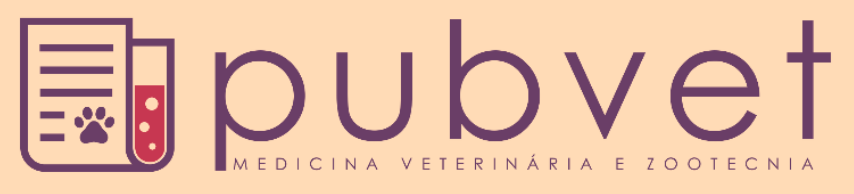

https://doi.org/10.31533/pubvet.v14n7a620.1-7

\title{
Sensibilização de crianças sobre tutoria responsável em cães e gatos
}

\author{
Renata Rocha da Silva ${ }^{1}$, , Anita de Souza Silva ${ }^{2}$, , Aécio Silva Júnior ${ }^{2} \bullet$,Maria Vitória Ferreira \\ $\operatorname{Santana}^{2}{ }^{\circ}$, Lucileide Andrade Santos ${ }^{\circ}{ }^{\circ}$, Victor Brenno Pereira Santos ${ }^{3}{ }^{\circ}$, Gregre Nicolas \\ Hernesto Santos $\operatorname{Silva}^{3}{ }^{\circ}$, Ana Cláudia Campos ${ }^{\circ} \mathcal{C D}^{\circ}$, Geyanna Dolores Lopes Nunes $^{4}{ }^{\circ}$, Roseane \\ Nunes de Santana Campos ${ }^{4 * \bullet}$
}

${ }^{I}$ Discente do Programa de Pós-graduação em Ciências da Saúde, Universidade Federal de Sergipe. Aracaju - SE Brasil.

${ }^{2}$ Discente do curso de Medicina Veterinária da Universidade Federal de Sergipe - Campus do Sertão. Nossa Senhora da Glória - SE Brasil.

${ }^{3}$ Médico Veterinário pela Universidade Federal de Sergipe - Campus do Sertão. Nossa Senhora da Glória - SE Brasil.

${ }^{4}$ Docente do Núcleo de Medicina Veterinária da Universidade Federal de Sergipe - Campus do Sertão. Nossa Senhora da Glória-SE Brasil.

*Autor para correspondência, E-mail: roseane_nunes@ hotmail.com

Resumo. A convivência com animais de estimação traz muitos benefícios aos seres humanos, no entanto, o desconhecimento dos fundamentos sobre a tutoria responsável e os cuidados inadequados com os cães e gatos alteram os padrões de crescimento populacional desses animais, afeta diretamente o bem-estar de todos os envolvidos e possibilita o aumento nas taxas de transmissão de doenças. A prática da guarda responsável assegura não somente o bem-estar e a saúde dos cães e gatos como também reduzem os danos à saúde pública. Esta ação teve como objetivo, sensibilizar crianças do ensino infantil e fundamental menor das escolas do alto sertão sergipano, Nordeste, Brasil sobre tutoria responsável em cães e gatos. A ação ocorreu de forma lúdica, com dramatização e brincadeiras e contou com vídeos interativos, teatro, jogos educativos, além da pintura facial com intenção de abordar os temas relacionados a tutoria responsável de animais de estimação, bem-estar animal e zoonoses. Ações que abordam tutoria responsável de cães e gatos com crianças são importantes na transformação das atitudes das crianças e futuro adultos em relação à responsabilidade com os animais de estimação.

Palavras-chaves: animais, guarda responsável, saúde pública, zoonoses

\section{Raising children's awareness about responsible guardianship with dogs and cats}

Abstract. Living with pets brings many benefits to humans, however, the unfamiliarity about the fundamentals responsible tutoring and inadequate care of dogs and cats change the patterns of population growth of these animals, and directly affect the well-being of all those involved and increases rates of disease transmission. The practice of responsible guardianship of these animals not only ensures the well-being and health of dogs and cats, but also reduces damage to public health. This project aimed to raise the awareness of children in kindergarten and lower elementary schools in the highlands of Sergipe, Northeast, Brazil about responsible tutoring in dogs and cats. The action took place in a playful way, with dramatization and games and featured interactive videos, a role play, educational games, as well as face painting with the intention of addressing topics related to responsible pet tutoring, animal welfare and zoonosis. Actions that address responsible tutoring of dogs and cats with children are important because it transforms the attitudes of children and future adults towards responsibility for pets.

Keywords: animals, public health, responsible guardianship, zoonosis 


\title{
Sensibilización de los niños sobre la tutoría responsable en perros y gatos
}

\begin{abstract}
Resumen. La convivencia con mascotas trae muchos beneficios para los seres humanos, sin embargo, la ignorancia de los fundamentos sobre la tutoría responsable y el cuidado inadecuado con perros y gatos altera los patrones de crecimiento poblacional de estos animales, afectando directamente el bienestar de todos aquellos involucrados y hace posible aumentar las tasas de transmisión de enfermedades. La práctica de la tutoría responsable no solo garantiza el bienestar y la salud de los perros y gatos, sino que también reduce el daño a la salud pública. Esta acción tuvo como objetivo sensibilizar a los niños (Cursos preescolar y educación básica primaria) en las escuelas de la región del alto sertão sergipiano, noreste de Brasil, sobre la tutoría responsable en perros y gatos. La acción tuvo lugar de una manera lúdica, con dramatización y juegos, y presentó videos interactivos, teatro, juegos educativos, así como pintura de caras con la intención de abordar temas relacionados con la tutoría responsable de mascotas, el bienestar animal y las zoonosis. Las acciones que abordan la tutoría responsable de perros y gatos con niños son importantes para transformar las actitudes de los niños y futuros adultos hacia la responsabilidad con las mascotas.
\end{abstract}

Palabras clave: animales, tutoría responsable, salud pública, zoonosis

\section{Introdução}

A convivência com animais agrega diversos benefícios psicológicos, fisiológicos e sociais aos seres humanos, mas pode causar, quando a criação de animais é inadequada, alteração dos padrões de bemestar dos animais, possibilidade de transmissão de doenças, ocorrências de agressões e contaminação ambiental (Lima \& Luna, 2012).

A Aliança Internacional para Controle de Animais de Companhia - ICAM (2007) conceitua a guarda responsável como princípio do bem-estar animal em que tutores têm o dever de fornecer cuidado apropriado a todos os seus animais e a seus descendentes. Estes também devem minimizar o risco potencial que seus animais podem representar para a população ou para outros animais.

O ensino de guarda responsável voltado às crianças é um recurso importante, pois nessa fase, elas estão desenvolvendo o caráter e durante essa etapa é essencial que tenham a percepção de que todas as formas de vida devem ser tratadas com respeito e responsabilidade (Ferreira et al., 2015). Desta forma, instruir sobre conceitos de tutoria responsável, bem-estar animal e zoonoses às criançascom brincadeiras é uma prática de ensino importante para a educação em saúde (Ishikura et al., 2017; Silvano et al., 2010).

Ações de extensão possibilitam que a comunidade acadêmica leve conhecimentos ao público externo e forme agentes multiplicadores (Ishikura et al., 2017). Além disso, os graduandos têm a oportunidade de iniciar um contato com a população local e conviver diretamente com tutores de animais de estimação (Budziak et al., 2017; Carvalho et al., 2017).

O presente trabalho foi delineado para orientar crianças do ensino fundamental inicial do sertão sergipano sobre a importância da tutoria responsável.

\section{Material e métodos}

Local e público-alvo

O projeto de extensão Essa Escola é o Bicho, vinculado à Universidade Federal de Sergipe (UFS), foi executado em escolas e universidade públicas dos municípios de Nossa Senhora da Glória, Canindé do São Francisco e Itabaiana, todas localizadas no sertão sergipano.

Foram selecionados como público-alvo da ação, crianças entre três e sete anos de idade (Educação Fundamental inicial).

As ações foram realizadas pelos discentes do curso de graduação em Medicina Veterinária, com orientação do docente responsável e contribuição de docentes e técnicos do Núcleo de Medicina Veterinária da Universidade Federal de Sergipe, Campus do Sertão. 


\section{Abordagem}

Antes das visitas, eram realizadas reuniões com os discentes para estudo sobre os temas abordados nas escolas, organização dos materiais e montar os brindes e atividade que seria entregue às crianças ao final das atividades. Além disso, antes da ação, era realizada uma visita à escola para uma conversa com diretores e observação do local e o que seria desenvolvido como as atividades lúdicas.

\section{Etapa 1: Atividade interativa}

Ao chegar às escolas, o primeiro contato com as crianças era padronizado pela apresentação do projeto e realização de questionamentos as crianças, para desse modo observar o conhecimento prévio das mesmas sobre tutoria responsável de animais de estimação.

\section{Etapa 2: Vídeos e músicas}

Durante a ação eram apresentados três vídeos com músicas interativas, abordando os temas de maus tratos e guarda responsável dos animais, transmitindo conceitos sobre a amizade dos cães e músicas que excluíam da versão antiga a parte dos maus tratos aos animais.

\section{Etapa 3: Teatro lúdico}

A apresentação de teatro lúdico (Figura 1) narrava a história de uma tutora com o seu cão bem cuidado e a amiga que não gostava de animais conversando em um parque. Estas avistam um cão abandonado e relatam os problemas de um animal não domiciliado. A amiga se apaixona pelo cão e resolve adotá-lo e com isso há um destaque para as cinco liberdades dos animais demonstrando a importância da higiene, alimentação, saúde e carinho aos animais. No final da apresentação, as crianças eram questionadas sobre os principais cuidados que deveriam ter com os animais de estimação.

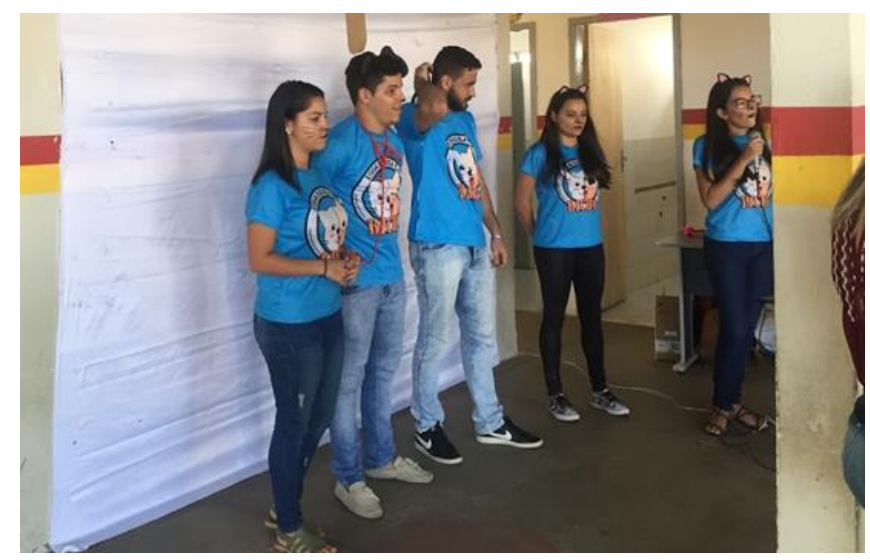

Figura 1. Apresentação do teatro lúdico sobre um cão abandonado

\section{Etapa 4. Atividades lúdicas}

Eram realizadas três atividades lúdicas, um jogo da memória com imagens de animais maltratados e após serem resgatados; jogo do agonista e antagonista (Figuras 2A e 2B ) para determinar o que o animal precisa para ser feliz, além da pintura facial de cães e gatos nos estudantes.

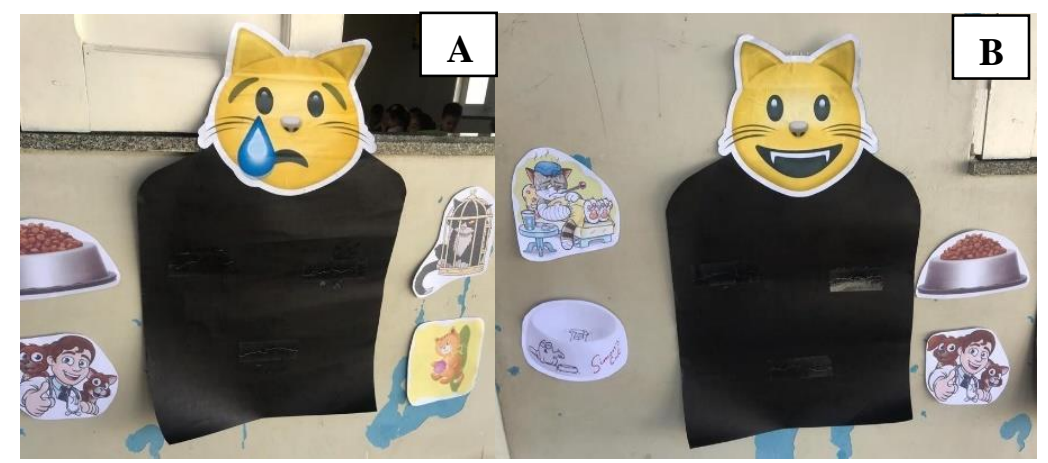

Figura 2. Jogo do agonista e antagonista. A. Animal triste. B. Animal feliz. 


\section{Etapa 5. Pintura facial}

A pintura do rosto (Figura 3), além de ser divertido para as crianças tinha a intenção de que quando chegassem a seus lares, pais, responsáveis e vizinhança, adquirissem curiosidade pelo desenho. Dessa forma, ao ser perguntada a criança iria informar sobre o conhecimento adquirido, relatando atitudes de tutoria responsável com os animais de estimação.

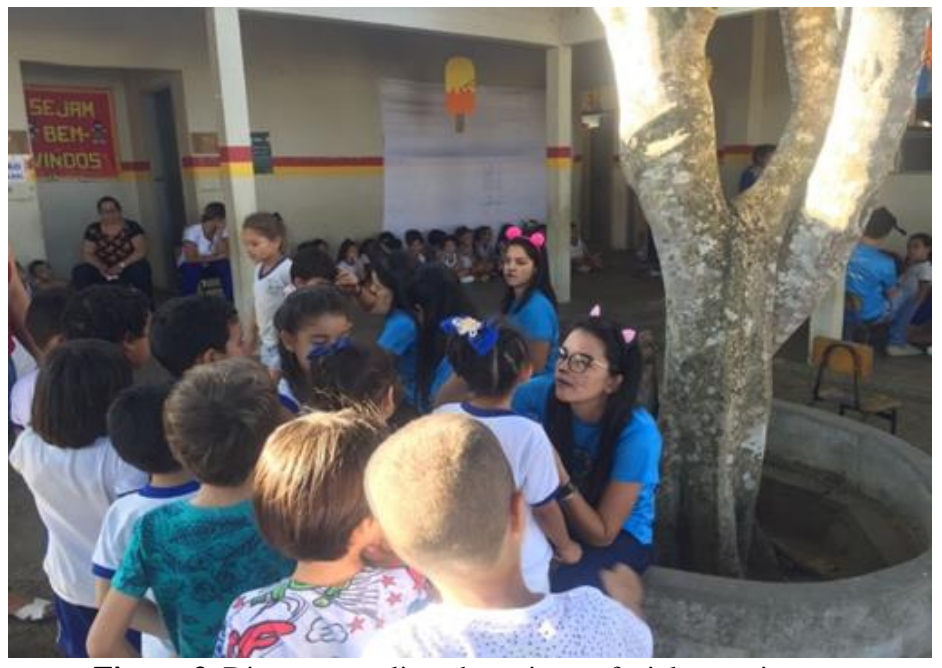

Figura 3. Discentes realizando a pintura facial nas crianças.

\section{Etapa 6. Panfletos e brindes}

Ao final das atividades, os professores e estudantes recebiam um panfleto sobre os principais cuidados com os animais domésticos (Figura 4) e atividades com desenhos de animais saudáveis para pintar que seriam compartilhadas no ambiente familiar (Figura5).

A direção de cada escola recebia um quadro com a logomarca do projeto e um cartaz com as cinco liberdades dos animais que eram expostos em local visível a todos que entravam na escola com a finalidade de retomar assuntos relacionados a liberdades dos animais e tutoria responsável constantemente.

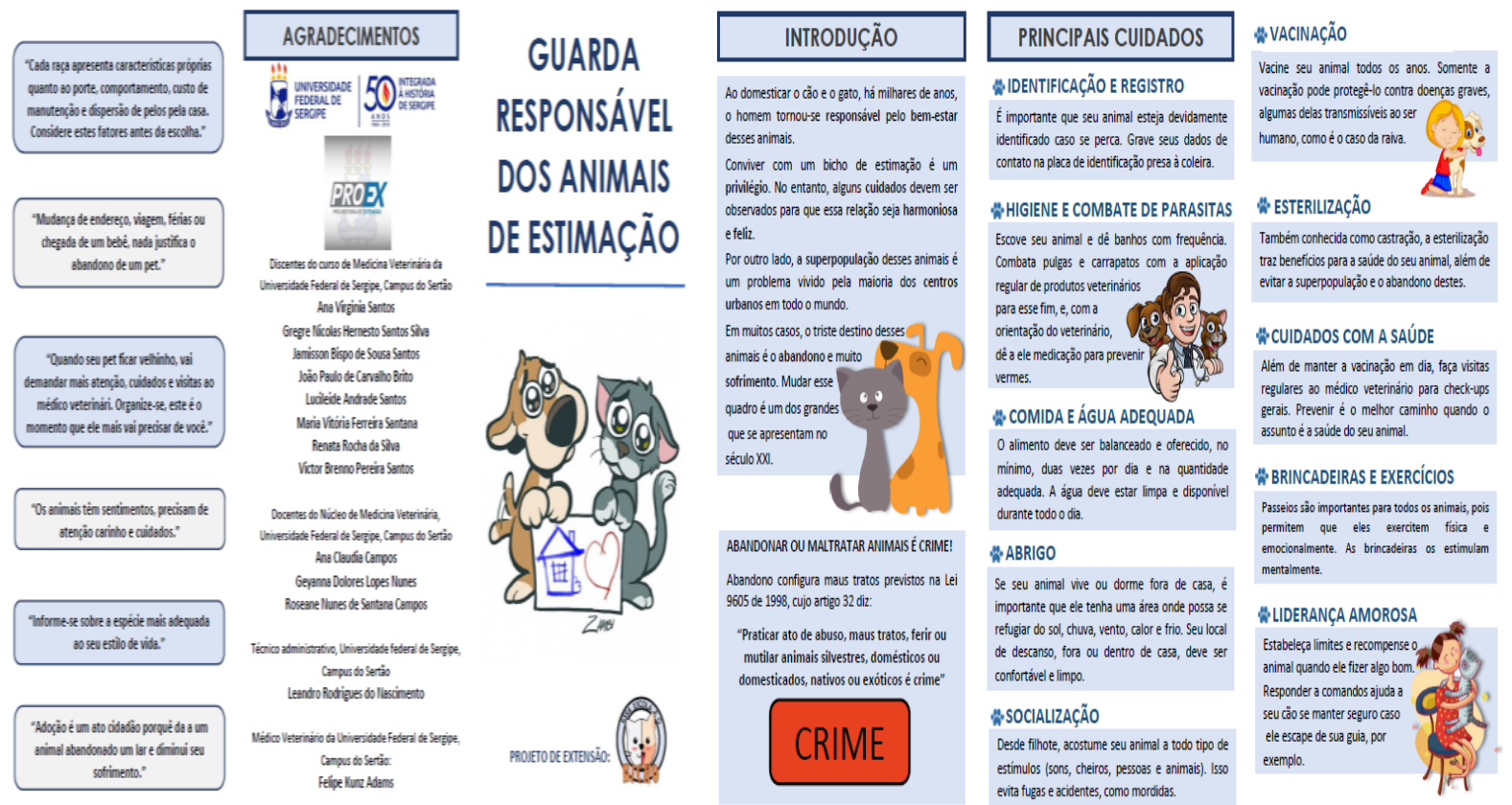

Figura 4. Panfleto educativo elaborado pelos discentes contendo informações sobre guarda responsável com os animais de estimação 


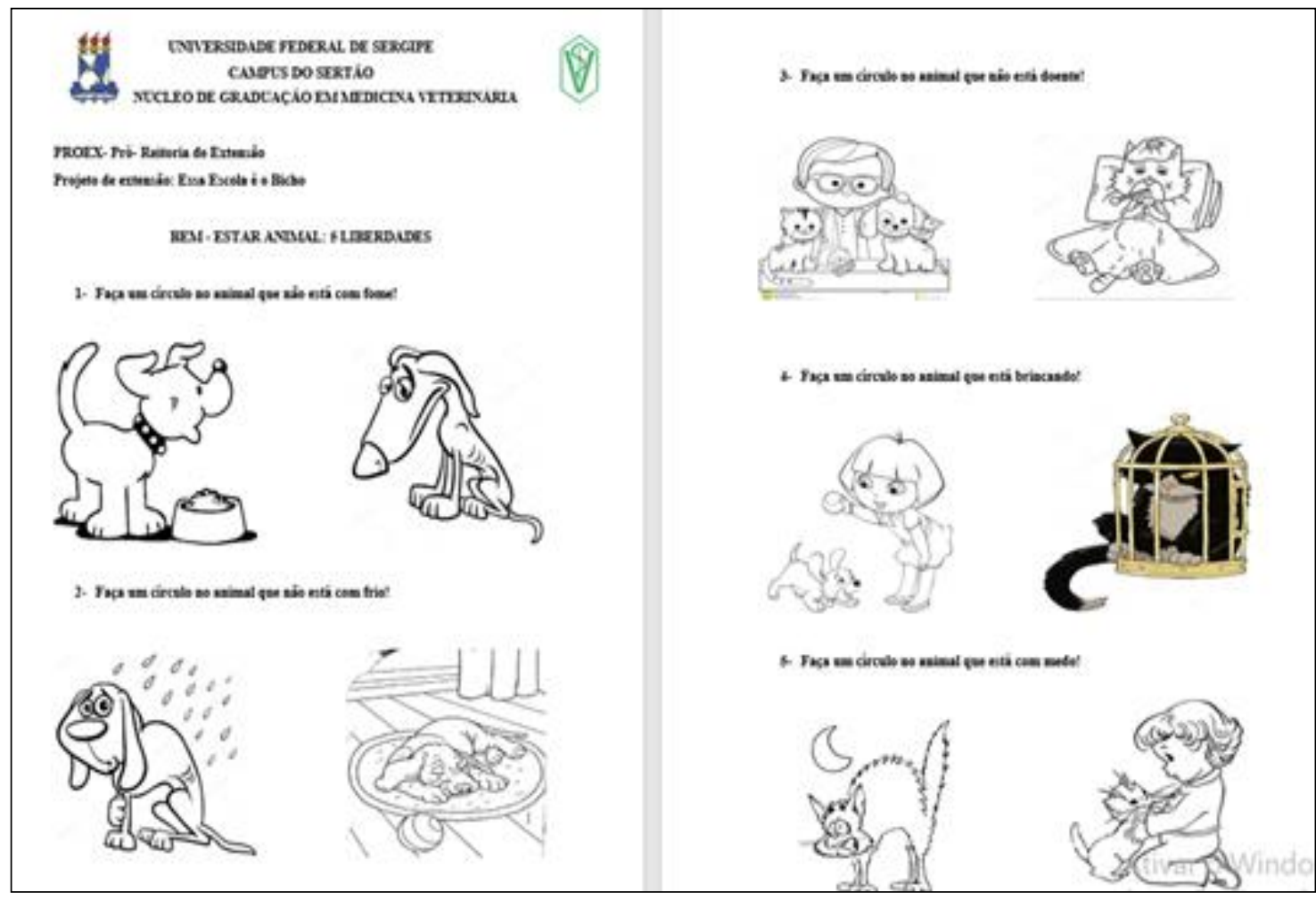

Figura 5. Atividade sobre as 5 liberdades dos animais

\section{Resultados e discussão}

Para prover a população com estas informações, foram realizadas nove ações, distribuídas em sete escolas e três eventos, respectivamente. $\mathrm{O}$ projeto orientou 1.876 crianças. Desta forma, contribuiu com o processo de formação das crianças e futuros adultos, em relação às atitudes relacionadas às responsabilidades com os animais de companhia, além de contribuir indiretamente com a transformação do pensamento dos familiares das crianças e servidores das escolas. Souza et al. (2016) afirmaram que trabalhos com educação e informações para crianças de noções básicas sobre os cuidados necessários com cães e gatos e tutoria responsável são essenciais para controlar a propagação de zoonoses, diminuir o abandono de animais, melhoria do bem-estar animal e da saúde pública do local.

Durante as ações, foi realizado o jogo do agonista e antagonista, o qual expressava as necessidades fisiológicas do animal, pois um dos motivos do comprometimento do bem-estar de cães e gatos é a falta de compreensão das suas necessidades e do comportamento natural das espécies. Muitos animais são adquiridos por impulsos e são, com frequência, seguidas de abandono, negligência ou maus-tratos (Lima \& Luna, 2012).

O conceito de brincadeira é entendido não apenas como uma forma de entretenimento, mas também, como um instrumento de auxílio no desenvolvimento infantil, que promove processos de socialização e descobrimento do mundo (Ishikura et al., 2017; Maluf, 2003) com isso, foram desenvolvidas brincadeiras lúdicas afim de promover a interação entre as crianças envolvidas.

Ao finalizar de cada ação, as crianças expressavam que os animais precisavam de um tutor atencioso, que fornecesse boa alimentação e proteção aos cães e gatos. Segundo Verçosa (2012) e Souza et al. (2016) a responsabilidade pelo mesmo é do tutor, uma vez que legalmente o animal não responde por si mesmo. As ações tiveram como foco a educação de crianças em fase inicial de formação do caráter com o objetivo de despertar o senso de responsabilidade, visando o respeito e preservação da dignidade dos animais, saúde e a vida dos mesmos e a relação destes cuidados com o bem-estar animal e a saúde pública. A implantação de programas educativos para a população sobre guarda responsável dos animais domésticos e dos riscos que as zoonoses são importantes para a saúde pública (Almeida et al., 2010; Cardoso et al., 2016; Sousa \& Silva, 2012). 
Uma das contribuições da Universidade na promoção de saúde é a ampliação do entendimento, essa atividade pode ser desenvolvida em espaços diversos, como por exemplo, nas escolas (Panegossi et al., 2017). Crianças informadas podem funcionar como difusores de temas tais quais zoonoses e bem-estar animal nas residências e comunidade, sendo capazes de atuar de forma relevante no conceito de tutoria responsável (Panegossi et al., 2017; Soto et al., 2006).

\section{Conclusão}

A sensibilização da comunidade, especialmente crianças, acerca do bem-estar animal é importante, pois colabora com a diminuição do abandono de cães e gatos, controla a propagação de zoonoses e promove melhorias na saúde pública local. Projetos de educação com crianças sobre tutoria responsável de cães e gatos contribuem com o processo de transformação nas atitudes dos futuros adultos em relação à responsabilidade com os animais de estimação.

\section{Agradecimentos}

Universidade Federal de Sergipe; Pro Reitoria de Extensão da UFS- PROEX; Diretores e professores das escolas estaduais e municipais do Sertão sergipano

\section{Referências bibliográficas}

Aliança Internacional para Controle de Animais de Companhia. - ICAM. (2007). Guia de controle humanitário $d a$ população canina,1-24. Disponível em: <https://www.icamcoalition.org/download/humane-dog-population-management-guidance-2007-version/>. Acesso em: 07 abr. 2020.

Almeida, P. A., Oliveira, J. R., \& Mantovani, M. M. (2010). Determinantes da interação homem-animal. PUBVET, 4(4), 144.

Budziak, C., Pimpão, C. T., Montoya, I. K., Júnior, J. A. V., \& Moraes, P. F. (2017). A importância do projeto Campanha de Castração na formação do profissional médico veterinário. Revista Acadêmica: Ciência Animal, 8(3), 361-370. DOI: https://doi.org/10.7213/cienciaanimal.v8i3.10946

Cardoso, D. P., Oliveira, R. P., Estrela, D. S., Saraiva, L. A., Farias, M. P. O., \& Silva, P. O. (2016). Perfil dos tutores de cão e gato no município de Bom Jesus-PI. PUBVET, 10(8), 580-635. DOI: https://doi.org/10.22256/pubvet.v10n8.580-586

Carvalho, S. M. R., Sousa, W. L., Rodrigues, A. A., Sá, M. V., Sá, I. S., Batista, R. M. O., Rocha, D. S., Santos, J. S., Galeno, L. S., \& Júnior, A. A. N. M. (2017). Atendimento clínico veterinário em cães e gatos na comunidade Serra Nova do município de Bom Jesus-PI. PUBVET, 12(2), 1-4. DOI: https://doi.org/10.22256/pubvet.v12n2a40.1-4

Ferreira, M. S. S., Aleixo, G. A. S., Melo, F. V. S., Xavier, A. N., Menezes, F. F., de Andrade, L. S. S., \& Coelho, M. C. de O. C. (2015). Incentivo à posse responsável e controle populacional de cães e gatos com ações educativas aplicadas a crianças de Garanhuns/PE. Revista de Educação Continuada Em Medicina Veterinária e Zootecnia Do CRMV-SP, 13(3), 80.

Ishikura, J. I., Cordeiro, C. T., Silva, E. C., Bueno, G. P., Santos, L. G., \& Oliveira, S. T. (2017). Minihospital veterinário: guarda responsável, bem estar animal, zoonoses e proteção à fauna exótica. Revista Brasileira de Extensão Universitária, 8(1), 23-30. DOI: https://doi.org/10.24317/2358$\underline{0399.2017 \mathrm{v} 8 \mathrm{i} 1.3123}$

Lima, A. F. M., \& Luna, S. P. L. (2012). Algumas causas e consequências da superpopulação canina e felina: acaso ou descaso? Revista de Educação Continuada Em Medicina Veterinária e Zootecnia, 10(1), 32-38. DOI: https://doi.org/10.36440/recmvz.v10i1.258

Maluf, A. C. M. (2003). A importância das brincadeiras na evolução dos processos de desenvolvimento humano. Revista Psicopedagogia OnLine.

Panegossi, M. F. C., Marques, A. E. G. W., L., S. N., Marques, M. G., Nagata, W. B., \& Bresciani, K. D. S. (2017). Necessidade de orientação dos tutores sobre posse responsável canina. Ars Veterinaria, 32(2), 88-91. DOI: https://doi.org/10.15361/2175-0106.2016v32n2p88-91

Silvano, D., Bendas, A. J. R., Miranda, M. G. N., Pinhão, R., Almeida, F. M., Labarthe, N. V, \& Paiva, 
J. P. (2010). Divulgação dos princípios da guarda responsável: uma vertente possível no trabalho de pesquisa a campo. Revista Eletrônica Novo Enfoque, 9(9), 64-86.

Soto, F. R. M., Risseto, M. R., Pinheiro, S. R., Souza, A. J., Portela, M. C., \& Lima, B. F. M. S. (2006). Avaliação de experiência com programa educativo de posse responsável em cães e gatos em escolas públicas de ensino fundamental da zona rural do município de Ibiúna, SP, Brasil. Revista Ciência Em Extensão, 2(2), 11-21.

Sousa, M. R. Q., \& Silva, F. B. S. (2012). Interação homem-animal e sua relação com a guarda responsável de cães em um bairro da cidade do Recife-PE. PUBVET, 6(5), 1-13. DOI: https://doi.org/10.22256/pubvet.v16n5.1294

Souza, A. F., Cruz, A. I. S., Rique, A. S., Brilhante, A. J. V. C., Farias, B. R. T., Rocha, J. J. G., \& Silva, S. V. (2016). O despertar da posse responsável na infância: saúde pública e cidadania. Revista Ciência Em Extensão, 12(4), 29-40.

Verçosa, A. H. (2012). Responsabilidade civil do Estado e de particulares em acidentes de trânsito provocados por animais: análise da doutrina da responsabilidade civil e apanhado da jurisprudência nacional. Jus Navigandi, 17, 1-4.

Recebido: 18 de abril, 2020.

Aprovado: 30 de maio, 2020.

Disponível online: 31 de julho, 2020

Licenciamento: Este artigo é publicado na modalidade Acesso Aberto sob a licença Creative Commons Atribuição 4.0 (CC-BY 4.0), a qual permite uso irrestrito, distribuição, reprodução em qualquer meio, desde que o autor e a fonte sejam devidamente creditados. 